\title{
Potentiating the effects of radiotherapy in rectal cancer: the role of aspirin, statins and metformin as adjuncts to therapy
}

\author{
K J Gash ${ }^{1,2,3}$, A C Chambers ${ }^{1,2,3}$, D E Cotton ${ }^{2}$, A C Williams ${ }^{*, 1}$ and M G Thomas ${ }^{1,2}$ \\ ${ }^{1}$ School of Cellular and Molecular Medicine, University of Bristol, Bristol BS1 8TD, UK and ${ }^{2}$ Department of Coloproctology, \\ University Hospitals Bristol NHS Foundation Trust, Bristol BS2 8HW, UK
}

Background: Complete tumour response $(\mathrm{PCR})$ to neo-adjuvant chemo-radiotherapy for rectal cancer is associated with a reduction in local recurrence and improved disease-free and overall survival, but is achieved in only 20-30\% of patients. Drug repurposing for anti-cancer treatments is gaining momentum, but the potential of such drugs as adjuncts, to increase tumour response to chemo-radiotherapy in rectal cancer, is only just beginning to be recognised.

Methods: A systematic literature search was conducted and all studies investigating the use of drugs to enhance response to neoadjuvant radiation in rectal cancer were included. 2137 studies were identified and following review 12 studies were extracted for full text review, 9 studies were included in the final analysis.

Results: The use of statins or aspirin during neo-adjuvant therapy was associated with a significantly higher rate of tumour downstaging. Statins were identified as a significant predictor of $\mathrm{PCR}$ and aspirin users had a greater 5-year progression-free survival and overall survival. Metformin use was associated with a significantly higher overall and disease-free survival, in a subset of diabetic patients.

Conclusions: Aspirin, metformin and statins are associated with increased downstaging of rectal tumours and thus may have a role as adjuncts to neoadjuvant treatment, highlighting a clear need for prospective randomised controlled trials to determine their true impact on tumour response and overall survival.

Advances in surgical resection (MacFarlane et al, 1993; Holm et al, 2007), development of adjuvant therapies (Gray et al, 2007; SebagMontefiore et al, 2009; Yaffee et al, 2015) and efforts to optimise early detection (National Cancer Intelligence Network, 2009), have led to a reduction in rectal cancer mortality rate (Office for National Statistics, 2014). Despite this, there are still high rates of local recurrence and systemic disease, which contribute to 5-year survival rates of less than $60 \%$ (Office for National Statistics, 2014). Poor response to adjuvant and neo-adjuvant treatment affects around $30-40 \%$ of patients and continues to pose a significant problem. Drug repurposing for anti-cancer treatments is gaining momentum, yet research into the utilisation of drugs as adjuncts, to enhance response to chemo/radiotherapy, is more limited. The purpose of this review is to explore evidence in the literature for such adjuncts; drugs that have been shown to increase tumour regression by enhancing the response of neo-adjuvant therapy in the management of patients with rectal cancer.

Concerns regarding the high rates of local recurrence of rectal cancer (Heald et al, 1982; Pilipshen et al, 1984; Nymann et al, 1995; den Dulk et al, 2009; Shihab et al, 2010) have catalysed the evolution of operative techniques, to facilitate more 'radical rectal resections', (e.g., Total Mesorectal Excision (TME) (MacFarlane et al, 1993) and Extra-Levator Abdomino-Perineal Excision (ELAPE) (Holm et al, 2007)). In addition, studies have examined the use of adjuvant and neo-adjuvant chemo- and/or radiotherapy, to ascertain which modality or combinations confer optimum benefit. Currently, in the UK, patients with rectal tumours at high risk of local recurrence (i.e., threatened mesorectal 
Table 1. Risk factors associated with local recurrence following rectal cancer surgery as predicted following staging using MRI pelvis, adapted from NICE guidelines 2014

\begin{tabular}{|l|l|l|}
\hline \multicolumn{2}{|l|}{ Characteristics of rectal tumours predicted by MRI } \\
\hline Low & Moderate & High \\
\hline $\begin{array}{l}\text { cT1-3a } \\
\text { No lymph }\end{array}$ & cT3b or greater & Threatened (<1 mm) or breached resection margin \\
node & Any suspicious lymph node NOT threatening surgical margin & Low tumours enchroaching inter-sphincteric plane or levator \\
involvement & Extramural vascular invasion & \\
\hline Abbreviation: MRI = magnetic resonance imaging. The risk of local recurrence helps to determine the use of neo-adjuvant therapy in rectal cancer.
\end{tabular}

resection margins or lymph node involvement, Table 1) are offered neo-adjuvant long-course chemo-radiotherapy (LCRT), followed by an interval to surgery to maximise response. The aims are to reduce tumour bulk to facilitate resection with a clear circumferential resection margin (CRM), minimise disease recurrence, and to increase sphincter-preserving surgery (NICE, 2014). Those deemed to be moderate risk (Table 1) are offered short-course preoperative radiotherapy (SCPRT) immediately prior to surgery. Numerous studies have now demonstrated that neo-adjuvant treatment improves oncological outcomes (Pahlman et al, 1997; Kapiteijn et al, 2001; Rullier et al, 2001; Sauer et al, 2004; Bosset et al, 2006; Peeters et al, 2007).

Tumour regression in response to neo-adjuvant chemo-radiation (Mandard et al, 1994; Wheeler et al, 2002) varies significantly between patients; some tumours undergo complete regression while others demonstrate no response (Dhadda et al, 2011). This can be graded by various systems, but commonly used is the American Joint Committee on Cancer (AJCC) criteria (Table 2), with regression classified as $0-3$, where 0 equates to a pathological complete response (pCR). The reasons for the disparity between patients in tumour regression are poorly understood. Several studies have investigated predictors of response, but have only demonstrated minor associations and reported inconsistent findings (de Campos-Lobato et al, 2011; Martin et al, 2012).

Around 20-30\% of tumours have a pCR (Mace et al, 2015), which is associated with a reduction in local recurrence and improved disease-free and overall survival (Rödel et al, 2005; Roh et al, 2009; Habr-Gama et al, 2010, 2013). Although pCR can be dependent on the quality of the surgical specimen and the accuracy of pathological examination can vary between pathologists (Chua, 2010), there appears to be increasing evidence to suggest that patients with pCR could be safely managed by local excision. Local procedures, such as Transanal Endoscopic Microsurgery (TEMS) or Transanal Endoscopic Operation (TEO), or indeed surveillance ('watch and wait' strategy), can potentially avoid the morbidity associated with resectional surgery and enable organ preservation (Han et al, 2015; Ryan et al, 2016). A recent systematic review suggests that local excision after neoadjuvant therapy for rectal cancer should only be considered as curative if complete pathological response is obtained, as pooled local recurrence rates were significantly lower and median disease-free survival significantly higher, for ypT0 tumours compared with ypT1 tumours or higher (Bach et al, 2009).

Therefore, optimising response to radiation is now fundamental to improving outcomes from rectal cancer, in both early and locally advanced stages. Studies are currently underway to extend the role of neo-adjuvant radiotherapy prior to the local excision of early rectal tumours, with the aim of treating microscopic lymph node metastases and reducing local recurrence (Leong et al, 2011, 2014). To identify patients whose tumours may be appropriate for local excision, studies have investigated the utilisation of biomarkers to predict mesorectal lymph node metastases. These studies have identified several biomarkers that have early promise, including the methylation of retinoic acid receptor $\beta(\operatorname{RAR} \beta)$, chemokine ligand 12 (CXCL12), and death-associated protein kinase 1 (DAPK1)
(TREC Trial Protocol, 2010; Leong et al, 2011, 2014). Potentially, radiation followed by local excision for early rectal cancers in patients with confirmed lymph node negativity may avoid resectional surgery in this patient group. This concept is currently being further explored in the TREC and future STAR-TREC trial (STAR-TREC Trial Protocol, 2016).

As malignancies develop they acquire both epigenetic and genetic changes that lead to therapy resistance and may promote evasion of apoptosis, an important 'hallmark of cancer' (Hanahan and Weinberg, 2011). The role of 'targeted adjuncts' to increase therapeutic response is becoming increasingly recognised. This concept suggests that established drugs with known anti-cancer properties, (but which are not primarily chemo-therapeutic agents), could be administered during neo-adjuvant therapy to sensitise cells and thus augment tumour response.

\section{MATERIALS AND METHODS}

This review examines the literature for potential adjuncts or supplementary treatments that may enhance the pathological response to neo-adjuvant therapy in rectal cancer. Systematic review and meta-analysis was attempted; a search was performed using Medline, Cochrane, Pubmed and Google Scholar databases with secondary searching of identified papers. The search terms used were: rectal cancer, radiotherapy, neoadjuvant, chemoradiation, metformin, aspirin and statins. We identified 2137 papers of which 9 studies were included in the final review (see Figure 1 for PRISMA flow diagram (Moher et al, 2009)). Due to the limited number of randomised controlled trials and the heterogeneity of relevant trials a narrative review has been conducted.

\section{DISCUSSION}

Statins as an adjunct to therapy. There is increasing evidence that statins may play an important role in reducing colorectal tumourigenesis, both in terms of disease prevention and improved survival (Siddiqui et al, 2009; Bardou et al, 2010). The term statin denotes a class of drug that inhibits the mevalonate pathway, which is critical for the production of the majority of organic compounds present in mammalian cells including steroids and cholesterol amongst other isoprenoid derivatives (Goldstein and Brown, 1990). Statins are synthetic inhibitors of hydroxymethylglutaryl coenzyme A reductase (HMGCoAR), a rate-limiting enzyme of the mevalonate pathway (Figure 2). Downstream products in the mevalonate pathway, such as farnesyl pyrophosphate, are molecules called isoprenoids. Isoprenylation (attachment of a molecule such as farnesyl pyrophosphate) is an important post-translational modification of proteins that enables their membrane attachment as part of their normal activity.

Statins were initially thought to drive colorectal carcinogenesis as early epidemiological studies showed an association between low cholesterol levels and increased colorectal cancer (Oliver, 1991). 
Table 2. The American Joint Committee on Cancer (AJCC) criteria for determining pathological response to neo-adjuvant radiotherapy in patients with rectal cancer, as determined by histological analysis after tumour resection, (Mace et al, 2015)

\begin{tabular}{|l|c|c|c|}
\hline \multicolumn{3}{|c|}{ AJCC criteria for pathological response to neo-adjuvant radiotherapy } \\
\hline $\mathbf{0}$ & $\mathbf{1}$ & $\mathbf{2}$ \\
\hline No viable tumour cells remaining & Single or small groups of tumour cells & Residual cancer outgrown by fibrosis & Minimal or no treatment effect \\
\hline Pathological complete response $(\mathrm{pCR})$ equates to a score of 0. & \\
\hline
\end{tabular}

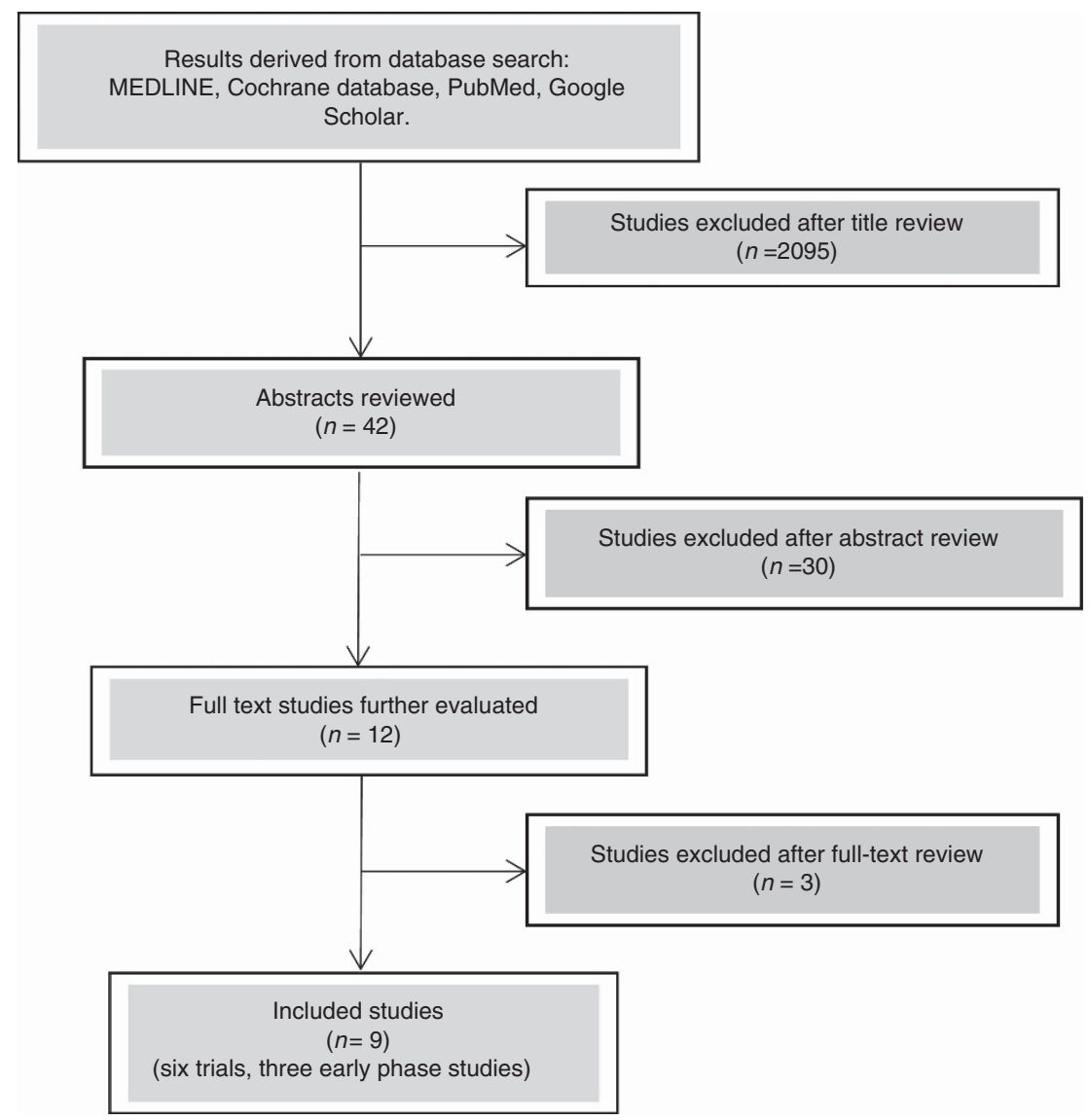

Figure 1. A PRISMA flow diagram showing the inclusion and exclusion of relevant studies. Due to the small number of studies yielded by the search criteria, the heterogeneity of outcomes and the diversity of adjuncts assessed, meta-analysis was not possible.

However numerous in vitro studies have highlighted that statins have a variety of effects in different tumour types (reviewed by Osmak, (2012)). It is now recognised that dysregulation of the mevalonate pathway itself can drive tumourigenesis in a cholesterol-independent manner (Clendening et al, 2010). In colorectal cancer, a number of mechanisms have been suggested for statins' protective effects. G-proteins such as RAS, important in colorectal cancer (Cox et al, 2014), undergo post-translational prenylation and early work suggested that RAS activation could be blocked by targeting this pathway (Schafer et al, 1989). Inhibition of the upper mevalonate pathway with lovastatin results in increased apoptosis in colorectal cancer cell lines, which could be abrogated with isoprenoid add-back (Agarwal et al, 1999). Moreover, mevastatin is thought to enhance the anti-proliferative effects of butyrate (a dietary short-chain fatty acid) in $\mathrm{Caco} 2$ colorectal cancer cells through inducing a cell cycle arrest (Wachtershauser, 2001). In addition to this, colorectal cancer cell invasion and metastasis are also thought to be targeted by statins (Kusama et al, 2003; Al-Haidari et al, 2014). Importantly in the context of this review, simvastatin has been shown to enhance the effect of radiation invitro on colorectal cancer cells by upregulating apoptosis in these cells (Lim et al, 2015).
Despite this in vitro evidence, it has been difficult to translate this to the bedside. Epidemiological work from the United Kingdom, analysed at two time points, showed that there was no difference in colorectal cancer risk with statin use (Vinogradova et al, 2007, 2011). Use of simvastatin as an adjunct to treatment in patients with metastatic colorectal cancer also failed to show any benefit to progression free survival in these patients (Lim et al, 2015). Furthermore, targeting KRAS expression, in patients who had KRAS mutant tumours, failed to enhance tumour sensitivity to panitumumab, suggesting that statins could not be used to modulate drug sensitivity in tumours with mutant KRAS (Baas et al, 2015).

Clinically, it may be that the beneficial effects of statins can be predicted by single-nucleotide polymorphisms (SNPs), such as the rs12654264 genotype. This genotype has been shown to modify the chemo-preventative effects of statins (Lipkin et al, 2010) and failure to control experimentally for this polymorphism could explain the current inconsistent results seen with adjunctive statin use.

Currently, translation of this pre-clinical work has been carried out in two studies analysing response of neo-adjuvant chemoradiotherapy (Katz et al, 2005; Mace et al, 2013) and a third paper 


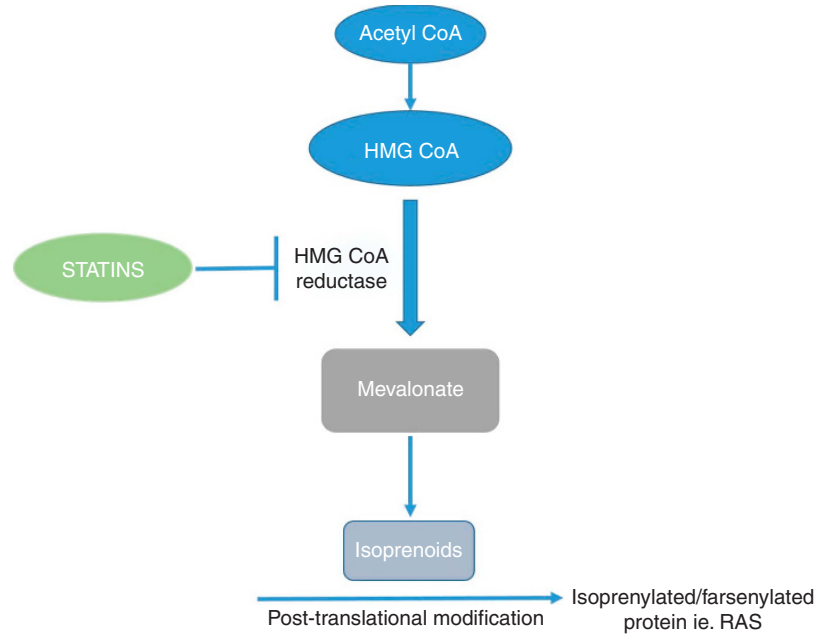

Figure 2. The mechanism of action of statins on the mevalonate pathway. Statins are competitive inhibitors of the enzyme 3-hydroxy-3methyl-glutaryl-coenzyme A reductase (HMG CoA reductase). This is a critical enzyme in the production of mevalonate and inhibition consequently reduces its derivatives, cholesterol, steroids and isoprenoids. Importantly in cancer, inhibition of this pathway reduces specific prenylated proteins, such as RAS.

which explored factors predictive of a pCR and identified statins as a significant predictor (Armstrong et al, 2015).

(Katz et al, 2005) analysed 349 patients from a prospective institutional database, of whom 33 were taking statins (33/ $349=9.5 \%$ ). Overall, $18.7 \%$ had a pCR. Univariate analysis showed that there was a non-significant trend towards a higher rate of pCR for statin users (30\%) compared with non-users $(17 \%, P=0.1)$. Only lower T-stage was found to be significantly associated with increasing pCR rate. An interesting subgroup analysis showed that of those patients taking statins, concomitant aspirin use was associated with a lower rate of pCR than for statin use alone ( $8 v s 47 \%)$. On multivariate regression analysis, having adjusted for concomitant aspirin/NSAID usage, statin use alone was significantly associated with pCR (OR 4.2; 1.7-12.1, $P<0.003)$ compared to non-statin use.

Following on from this, Mace et al (2013) performed a retrospective cohort study, using a prospectively maintained database of patients with rectal cancer undergoing neo-adjuvant chemo-radiotherapy. They identified 407 eligible patients of whom 99 were statin users $(24.3 \%)$ and showed that statin users were less likely to exhibit no response to neo-adjuvant therapy (i.e., AJCC Regression Grade 3) (11.1\%) compared to non-users (19.8\%, $P=0.049$ ). In both univariate and multivariate analyses, statin use was a significant predictor of AJCC response (Grade 0-1), (OR, $2.25 ; 95 \%$ CI, 1.33-3.82), as was the absence of lymphovascular invasion. Moreover, statin users were more likely to have had a near-complete or complete response (i.e., Regression Grade 0 or 1), (65.7 vs 48.7\%, $P=0.004$ ). Despite this, there was no significant difference in pCR rates (AJCC grade 0), between statin users $(25.2 \%)$ and non-users $(20.8 \%, P=0.35)$. Potential bias in this study was introduced as the statin group were significantly older, had higher BMIs, worse American Society of Anesthesiologists (ASA) grades and a greater proportion of male patients than the non-statin group. Furthermore, there was a higher incidence of lymphovascular invasion in tumours of the statin users $(11.1 \mathrm{vs}$ $5.2 \%, P=0.04)$. However, the generalisability of the study benefitted as a variety of different statins were used, including Atorvastatin, Simvastatin, Rosuvastatin, Lovastatin and Pravastatin, during its course.

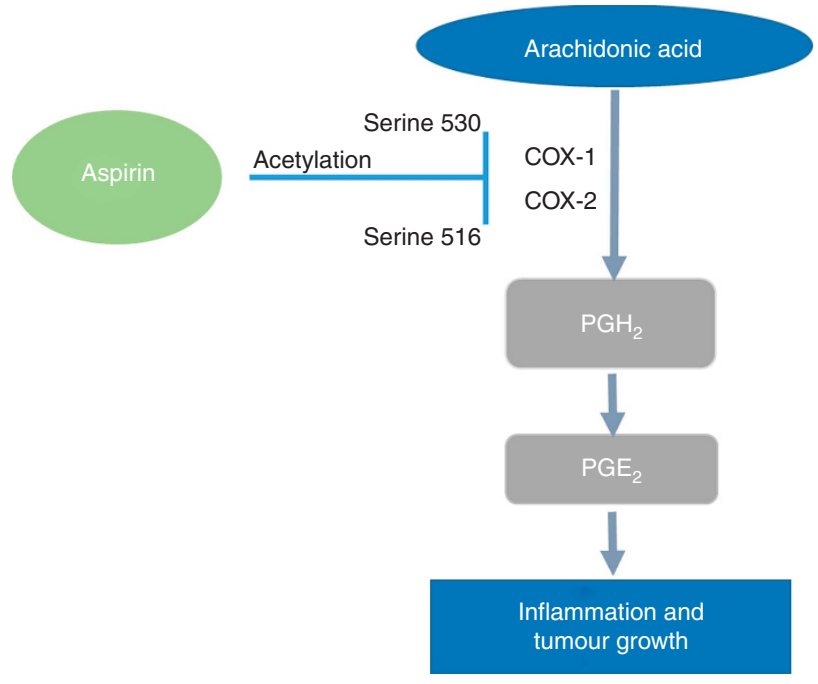

Figure 3. The cyclo-oxygenase dependent mechanism of action of aspirin. Aspirin treatment causes the post-translational modification of cyclo-oxygenase (Cox) proteins by acetylating serine residues $\left(\mathrm{Cox}-1^{\mathrm{Ser} 530}\right.$ and Cox- $2^{\text {Ser516) }}$ on either Cox- 1 \& Cox- 2 enzymes. This prevents arachidonic acid from accessing the catalytic site on the Cox enzymes. As a result there is reduced formation of the precursor for all prostaglandins (PGs) and therefore lower levels of prostaglandin $\mathrm{E}_{2}\left(\mathrm{PGE}_{2}\right)$.

Finally, a study by Armstrong et al (2015) analysed factors predictive of pCR following neo-adjuvant chemo-radiotherapy for rectal cancer. Of 885 patients, $18 \%$ of patients had a pCR and on univariate analysis, only lower CEA and higher $\mathrm{Hb}$ were associated with a pCR. In addition, multivariate analysis showed statin use was significantly predictive of pCR (OR, 1.72; 95\% CI 1.02-2.92, $P=0.04)$. Other factors included decreased distance from the anal verge and lower pre-operative CEA. pCR was significantly associated an improved 3-year disease-free survival (HR, 0.31; 95\% CI $0.20-0.48, P<0.0001)$ and with overall survival (HR, 0.29; 95\% CI 0.17-0.51, $P<0.0001)$, compared with non-pCR.

Aspirin: teaching an old drug new tricks. For over three decades the role of aspirin in reducing colorectal cancer risk has been explored in a number of settings; in particular, for high-risk patients with FAP (Waddell and Loughry, 1983; Giardiello et al, 1993), HNPCC (Burn et al, 2011), patients already treated for colorectal adenomas (Baron et al, 2003), and for colorectal carcinomas (Rothwell et al, 2012). Similarly, long-term vascular studies of regular low-dose aspirin users have highlighted the significant reduction in colorectal cancer rates and mortality (Rothwell et al, 2010). However, until recently, the use of aspirin as an adjunct to treatment has been somewhat overlooked (Restivo et al, 2015).

Aspirin inhibits the cyclo-oxygenase (COX) enzymes by the acetylation of serine 530 (COX-1) and of serine 516 (COX-2; Figure 3). This precludes arachidonic acid from accessing the catalytic site on the COX enzyme, preventing it from being metabolised and thus blocking prostaglandin formation (Roth et al, 1975). The COX-2-derived prostaglandin, PGE2, is over expressed in colorectal cancer and has been shown to promote tumour growth by binding to the EP transmembrane G-protein-coupled receptors, which activates pathways for gene transcription, proliferation, angiogenesis and inhibits apoptosis (Wang, 2006). This ultimately activates downstream signalling pathways that can increase tumour cell survival, proliferation and migration (Greenhough et al, 2009; Wang and DuBois, 2009). Those patients with colorectal cancers that have an increased COX-2 expression, 
have been found to have reduced 5-year survival, increased metastases and higher rates of local recurrence compared to those without elevated COX-2. Aspirin is thought to potentially exhibit its chemo-preventative properties independently of $\mathrm{PGE}_{2}$ through the COX derived antiplatelet effect. Aspirin has been found to be 100 times more powerful at inhibiting platelet COX-1 compared with COX-2 (Piazuelo and Lanas, 2015). Blocking COX-1 activity suppresses thromboxane $\mathrm{A}_{2}\left(\mathrm{TXA}_{2}\right)$ synthesis, inhibiting platelet aggregation. Platelets have a limited capacity of protein synthesis, whereas nucleated cells such as monocytes (with COX-2) resynthesise the enzyme rapidly; enzymes are only temporarily and partially inhibited. Furthermore, aspirin's half-life is $\sim 20 \mathrm{~min}$, therefore, only a low dose of around $75 \mathrm{mg}$ is required to maximally inhibit platelets and the effect lasts $24 \mathrm{~h}$, whereas COX-2 suppression necessitates higher and more regular doses.

The cancer stem cell hypothesis suggests that within tumours a small population of cells, colorectal cancer stem cells (CSC), are the driving force behind carcinogenesis: triggering gene transcription; maintaining tumour growth and ultimately fuelling resistance to chemo-radiation and instigating disease recurrence (Cho and Clarke, 2008). The COX-2/PGE 2 pathway has been shown to stimulate the function and survival of colorectal CSC through upregulating leucine-rich repeat-containing G-protein-coupled receptor 5 (Lgr5) expression (Al-Kharusi et al, 2013). Lgr5 is an intestinal stem cell marker (Barker et al, 2007) and a Wnt target gene (Van der Flier et al, 2007). Wnt signalling is an essential driving force of the overall biology of the intestinal crypt (Korinek et al, 1998). The activation of aberrant $\mathrm{Wnt} / \beta$-catenin signalling is a critical early step in the majority of colorectal cancers with most tumours harbouring APC or $\beta$-catenin mutations; leading to enrichment of colorectal cancer stem cells (Morin et al, 1997).

Tumourigenesis can trigger the production of inflammatory mediators, which result in an increase in prostaglandin synthesis and contribute to the development of an inflammatory microenvironment (Mantovani et al, 2008). NF- $\kappa \mathrm{B}$ is a key transcription factor in the development of such an environment. NF- $\kappa \mathrm{B}$ also has a crucial role in epithelial cells, regulating genes that control cell survival, viral replication and autoimmune function (Bharti and Aggarwal, 2002), thus providing a key link between inflammation and cancer (Karin and Greten, 2005). The release of cytokines and inflammatory signals stimulates the action of NF- $\kappa \mathrm{B}$ in epithelial cells, which subsequently promotes the survival of cancer cells. Furthermore, expression of the NF- $\kappa \mathrm{B}$ co-regulators, such as BCL3 , has been shown to worsen prognosis in colorectal cancer (Puvvada et al, 2010; Saamarthy et al, 2015), highlighting the importance of the whole pathway.

To summarise, in vitro and in vivo pre-clinical work has shown that aspirin may well target a number of different pathways within the tumour cell including the promotion of a cancer stem cell phenotype and the inhibition of tumour microenvironment associated inflammation.

Despite the quantity of pre-clinical studies there are very few studies examining aspirin as an adjunct in patients. Restivo et al performed a prospective observational cohort study of all patients with Stage II or III rectal cancer undergoing neo-adjuvant chemoradiation (Restivo et al, 2015). Of the 241 patients identified, 37 in the 'aspirin-use' group were compared with 204 controls (no aspirin-use). All 37 patients were taking $100 \mathrm{mg}$ of aspirin as cardiovascular risk prevention, with a median duration of use preoperatively of 5 years. Patients were treated with $45 \mathrm{~Gy}$ of radiotherapy over five weeks (as 25 fractions of $1.8 \mathrm{~Gy}$ using a 3 -field technique with tumour boost of $9 \mathrm{~Gy}$. Chemotherapy was Capecitabine $1650 \mathrm{mg} \mathrm{m}^{-2}$. The primary outcome of the study was a 'good pathological response' (GPR), defined as downstaging to T0 or T1, N0 disease. GPR was significantly higher in the aspirin group compared to the non-aspirin users (46 vs 19\%, $P<0.001$ ). Furthermore, aspirin use was associated with a significantly higher rate of tumour downstaging (to any stage) (67.6 vs 43.6\%, $P=0.011)$. The rate of complete pathological response (pCR) was also higher in the aspirin group, although this did not reach statistical significance (22 vs $13 \%, P=0.196$ ). It should be noted that patients in the non-aspirin group had a much higher rate of diagnosis of metastasis pre-operatively. Although the aspirin-use group had a higher median age (71 vs 64 years, $P<0.001)$ and higher rate of comorbidity (Charlson Score 3-4), (40.5 v 17.6\%, $P<0.004$ ), the two groups were comparable in terms of preoperative $\mathrm{T}$ and $\mathrm{N}$-stage, tumour size, grade and CEA. Aspirin-use was also associated with a better 5 -year progression-free survival (86.6 vs 67.1\%; $\mathrm{HR}=0.20 ; 95 \% \mathrm{CI}=0.07-0.6)$ and overall survival (90.6 vs 73.2\%; $\mathrm{HR}=0.21,95 \% \mathrm{CI}=0.05-0.89$ ). Cox regression analysis confirmed that aspirin was the only significant factor predictive of progression-free and overall survival.

Interestingly, more patients on aspirin underwent the minimally invasive transanal endoscopic microsurgery (TEM) as their definitive primary surgical procedure (13.5 vs 2.5\%, $P=0.017$ ). The authors state that the decision to proceed to TEM was based on significant downstaging by neoadjuvant chemo-radiotherapy.

Metformin: from folk remedy to anti-cancer drug. Metformin is a biguanide that is typically used as an oral anti-hyperglycaemic in patients with type 2 diabetes mellitus. Metformin acts to lower plasma glucose levels by decreasing hepatic gluconeogenesis, decreasing intestinal glucose absorption and increasing peripheral glucose uptake (Lee and Kim, 2014). Epidemiological studies and subsequent meta-analyses, suggest that metformin reduces the risk of developing a number of malignancies such as breast, gastrointestinal, lung and hepatocellular carcinoma (Rizos and Elisaf, 2013). More recently, its role as adjunct to therapy for the treatment of several cancers has been explored (Coyle et al, 2016). In colorectal cancer, metformin's anti-neoplastic effects are thought to be derived through a number of mechanisms. Primarily metformin can directly or indirectly activate 5' adenosine monophosphate-activated protein kinase (AMPK), which leads to downregulation of mammalian Target Of Rapamycin complex 1 (mTORC1) and resultant inhibition of tumour progression or induction of apoptosis (a review of the mTOR pathway (Guertin and Sabatini, 2007); Figure 4). Furthermore, AMPK independent regulation of mTORC1 by metformin occurs through REDD1 (regulated in development and DNA damage responses 1) or by Rag proteins in the 'Ragulator complex' (Pierotti et al, 2013).

Functional studies in colorectal cancer models have shown that metformin can potentiate the effects of other anti-cancer therapies such as mesalazine (Saber et al, 2016). Alongside this, metformin has been shown to induce radiosensitivity in vitro, in a radioresistant p53 colorectal cancer cell line, by prolonging cell-cycle arrest and inhibiting DNA repair proteins (Jeong et al, 2015). Radiosensitisation has also been reported to occur by metformin through decreasing cancer oxygen consumption thereby lessening the tumour promoting effects of tumour hypoxia (Zannella et al, 2013). In addition, this work was corroborated in 3D tumour spheroids which showed improved responses to radiation in colorectal cancer cell lines after metformin treatment had reduced spheroid oxygen consumption rates (Ashton et al, 2016). These in vitro reports highlight a novel role for metformin not only as a cancer risk-reducing drug but also one that could be used as an adjunct to conventional neo-adjuvant or adjuvant therapies in rectal cancer.

A clinical study by Skinner et al examined the effect of metformin use on response to neoadjuvant therapy (Skinner et al, 2013). Patients with rectal adenocarcinoma were divided into 3 groups: non-diabetics (422 patients), diabetics not taking metformin (40 patients) and diabetics on metformin (20 patients). All patients had neoadjuvant chemoradiation, with radiotherapy administered with 3D conformational technique and 


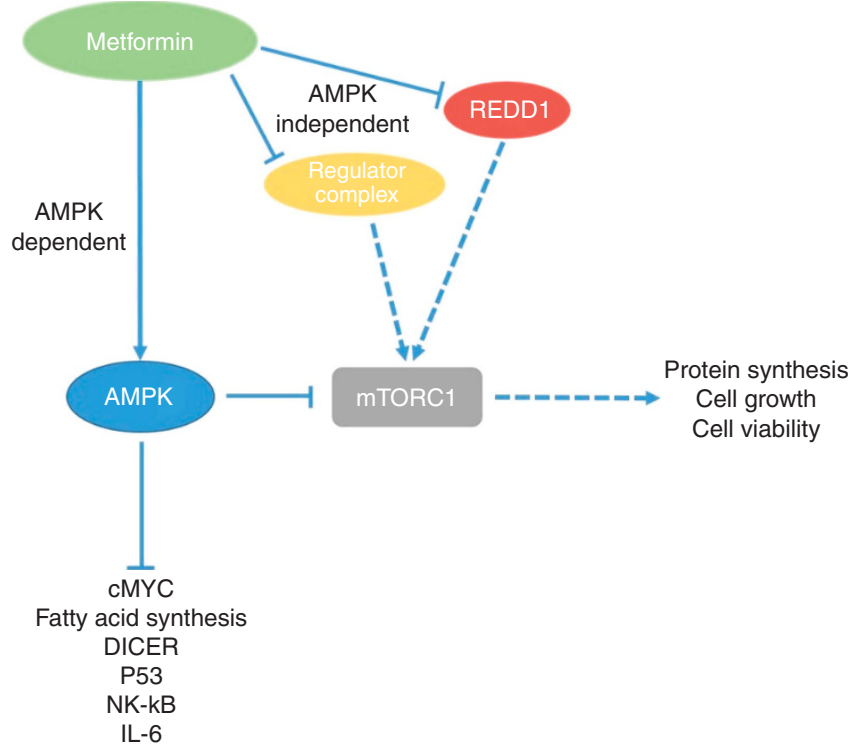

Figure 4. The mechanism of action of metformin. Metformin has both AMP-activated protein kinase (AMPK) dependent and independent mechanisms of action. Although, both these mechanisms can converge by inhibiting 'mammalian target of rapamycin complex 1' (mTORC1). AMPK is activated by metformin, resulting in downregulation mTORC1 and subsequent inhibition of tumour progression. Furthermore, metformin inhibits both the ragulator complex and 'regulated in development and DNA damage response 1' (REDD1) which subsequently results in inhibition of mTORC1.

chemotherapy given with either 5FU (53\%) or capecitabine (45\%). Across all groups, there was a $17 \%$ rate of pCR. Diabetics on metformin had a higher rate of pCR than diabetics not on metformin and the non-diabetic patients, (35 vs 7.5 vs 16.6\%, $P=0.03)$. ANOVA confirmed that being diabetic and taking metformin was significantly associated with pCR $(P=0.03)$. Metformin use was associated with a higher overall $(P<0.001)$ and disease-free $(P<0.001)$ survival, at both five and ten years, compared with diabetics not taking metformin. Interestingly, diabetic patients not taking metformin had a greater median tumour size $(6 \mathrm{~cm})$ than those in the diabetic on metformin $(4.5 \mathrm{~cm})$ and non-diabetic $(5 \mathrm{~cm})$ groups $(P=0.01)$ possibly leading to confounding. Crucially there was no control experimental arm analysing response in patients given metformin who were not diabetic, something only achievable as part of a randomised control trial.

Oh et al (2016) analysed the role of metformin as an adjunct to radiation, using similar patient groups as above (Skinner et al, 2013). The crossover design resulted in two cohorts of patients, in which there were no significant differences in tumour characteristics, although the non-diabetic group was younger $(P<0.001)$ and had a lower BMI $(P=0.012)$. All patients had T3 or T4 tumours, were node positive, and had tumours $<12 \mathrm{~cm}$ from the anal verge. They received radiotherapy (44-54 Gy fractionated as $1.2-2$ Gy for 5 days a week) and chemotherapy (either $5 \mathrm{FU}$ and leucovorin $(66 \%)$ or capecitabine). Tumour response was graded as either a decrease in T-stage, a decrease in N-stage, or a pCR. The study also assessed the pathological stage of response according to Dworak's tumour regression grade (TRG) (Table 3) (Dworak et al, 1997). For comparative analysis the TRG was categorised as 'non responders' (TRG 0-2) and 'responders' (TRG 3-4).

On multivariate analysis, in both time cohorts, there was a significantly higher rate of TRG 3-4 (good/complete response) in the metformin group, $(P=0.019$ and $P=0.044)$, although no difference in pCR. In the later cohort, metformin use was predictive of T-stage downstaging $(P=0.013)$, but there was no significant difference in $\mathrm{N}$ (nodal status) downstaging. For the earlier cohort the opposite was true; metformin use was associated with $\mathrm{N}$-downstaging $(P=0.003)$ but not significant T-stage downstaging.

There was no significant difference in local recurrence-free survival, disease-free survival or overall survival between the groups. Metformin use was not a significant predictor for any type of survival in a Cox proportional hazards model.

Further adjuncts to neoadjuvant therapies. Three papers were identified that outlined preliminary investigations (phase I or II studies) piloting non-chemotherapeutic agents as adjuncts to neoadjuvant chemo-radiotherapy (Wang et al, 2014; Illum et al, 2015; Stoffregen et al, 2016). Illum et al conducted a phase I, feasibility, cohort study investigating the safety, toxicity and optimum dose for nitroglycerin patches (nitric oxide donor) when used as an adjunct to neoadjuvant 5-fluorouracil and radiation in rectal cancer. There was no control group for comparison of outcomes, but the patches were well tolerated in the 13 patients studied, with minimal side effects and an overall pCR rate of $17 \%$.

Supplementation with folic acid and vitamin $\mathrm{B}_{12}$ in patients receiving Permetrexed (a multitargeted antifolate drug) as a single neo-adjuvant chemotherapeutic agent ( \pm radiotherapy) for rectal cancer, was assessed by Stoffregen et al (2016), They concluded that the regimen was feasible and tolerable. Levels of 'reduced folates' in tumours and various markers of vitamin metabolism were recorded and noted to fluctuate with the adjunct treatment, although this is of uncertain clinical value and is being further investigated.

Finally, further work examined the use of anti-inflammatory drugs; Wang et al conducted a phase II study examining the use of the NSAID celecoxib ( $400 \mathrm{mg}$ per day) in patients receiving neoadjuvant treatment for locally advanced rectal cancer (Stage II or III). Of the 47 patients included (who received celecoxib, CRT and surgery), pCR rate was $13 \%(n=6)$ and tumour downstaging occurred in $81 \%(n=38)$. Tumour tissue was analysed for COX-2 expression; high levels of COX-2 following treatment were associated with reduced pelvic control and poorer disease-free and overall survival, than in those with low COX-2 expression. However, the use of celecoxib is limited given the significant increase in vascular and cardiac side effects (Bhala et al, 2013).

\section{CONCLUSION}

Tumour regression following neo-adjuvant chemo-radiotherapy has been shown to be significantly associated with five-year overall survival, disease-free survival and local recurrence (Mace et al, 2015). There is, therefore, increasing interest in developing our understanding of treatment adjuncts to enhance tumour response to therapy. Current evidence suggests that the use of adjuncts to neoadjuvant treatment may improve outcomes by increasing the likelihood of pathologically complete or near-complete response in patients with rectal cancer.

If pCR truly allows a 'watch and wait' strategy, and if tumour downstaging facilitates local excision, such as TEMS/TEO, without affecting survival, then any treatment that may augment pCR rates should be fully explored.

Drug repurposing provides the opportunity to quickly translate basic science research into clinical therapies. Moreover, the repurposing of common drugs like aspirin, statins and metformin is promising, as the drug profile and associated side effects, risks and tolerance are well documented. However, the evidence for their routine use is as yet limited. All data we have analysed are within retrospective cohort studies in patients taking the drug for other indications. 


\begin{tabular}{|c|c|c|c|c|}
\hline \multicolumn{5}{|c|}{ Dworak's tumour regression grade } \\
\hline 0 & 1 & 2 & 3 & 4 \\
\hline No regression & $\begin{array}{c}\text { Dominant tumour mass with } \\
\text { obvious fibrosis and/or } \\
\text { vasculopathy }\end{array}$ & $\begin{array}{l}\text { Dominantly fibrotic changes with } \\
\text { few tumour cells or groups } \\
\text { (easy to find) }\end{array}$ & $\begin{array}{l}\text { Very few (difficult to find } \\
\text { microscopically) tumour cells in } \\
\text { fibrotic tissue with or without } \\
\text { mucous substance }\end{array}$ & $\begin{array}{l}\text { No tumour cells, only fibrotic mass } \\
\text { (total regression or response) }\end{array}$ \\
\hline
\end{tabular}

The studies we have identified support the notion of a treatment effect of statins, aspirin and metformin. Each of these adjuncts appear to be associated with increased downstaging of tumours (supported in all publications), however the association with pCR is less clear. In only one report (Armstrong et al, 2015) statin use was identified on multivariate analysis as being an independent predictor of $\mathrm{pCR}$.

Despite this potential, the literature contained only a small number of relevant studies, assessing three main adjuncts and used a variety of outcome measures; thus the heterogeneity of results meant that it was not possible to perform a meta-analysis on the data. Furthermore, any new drugs given to patients already burdened by a diagnosis of cancer, radiotherapy treatment and the side effects of long course chemotherapy need to have proven efficacy. There is a clear need for prospective randomised controlled trials to investigate these adjuncts, singularly or in combination, to determine whether they confer and increase in response to neo-adjuvant therapy or a long-term effect on survival.

\section{ACKNOWLEDGEMENTS}

This work was supported by a Royal College of Surgeons of England Research Scholarship (funded by Rosetrees Trust) (KG), an MRC Clinical Research Training Fellowship (ACC), The David Telling Charitable Trust (KG \& ACC), The Above \& Beyond Charitable Trust (KG), John James Foundation (KG, ACC, ACW) and Cancer Research UK (ACW). Manuscript has not been presented at time of submission.

CONFLICT OF INTEREST

The authors declare no conflict of interest.

\section{REFERENCES}

Agarwal B, Bhendwal S, Halmos B, Moss SF, Ramey WG, Holt PR (1999) Lovastatin augments apoptosis induced by chemotherapeutic agents in colon cancer cells. Clin Cancer Res 5(8): 2223-2229.

Al-Haidari AA, Syk I, Thorlacius H (2014) HMG-CoA reductase regulates CCL17-induced colon cancer cell migration via geranylgeranylation and RhoA activation. Biochem Biophys Res Commun 446(1): 68-72.

Al-Kharusi MRA, Smartt HJM, Greenhough A, Collard TJ, Emery ED, Williams AC, Paraskeva C (2013) LGR5 promotes survival in human colorectal adenoma cells and is upregulated by PGE(2): implications for targeting adenoma stem cells with NSAIDs. Carcinogenesis 34(5): 1150-1157.

Armstrong D, Raissouni S, Price Hiller J, Mercer J, Powell E, MacLean A, Jiang M, Doll C, Goodwin R, Batuyong E, Zhou K, Monzon JG, Tang PA, Heng DY, Cheung WY, Vickers MM (2015) Predictors of pathologic complete response after neoadjuvant treatment for rectal cancer: A Multicenter Study. Clin Colorectal Cancer 14(4): 291-295.
Ashton TM, Fokas E, Kunz-Schughart LA, Folkes LK, Anbalagan S, Huether M, Kelly CJ, Pirovano G, Buffa FM, Hammond EM, Stratford M, Muschel RJ, Higgins GS, McKenna WG (2016) The anti-malarial atovaquone increases radiosensitivity by alleviating tumour hypoxia. Nat Commun 7: 12308.

Baas JM, Krens LL, ten Tije AJ, Erdkamp F, van Wezel T, Morreau H, Gelderblom H, Guchelaar HJ (2015) Safety and efficacy of the addition of simvastatin to cetuximab in previously treated KRAS mutant metastatic colorectal cancer patients. Invest New Drugs 33(6): 1242-1247.

Bach SP, Hill J, Monson JRT, Simson JNL, Lane L, Merrie A, Warren B, Mortensen NJM (2009) A predictive model for local recurrence after transanal endoscopic microsurgery for rectal cancer. Br J Surg 96(3): 280-290.

Bardou M, Barkun A, Martel M (2010) Effect of statin therapy on colorectal cancer. Gut 59(11): 1572-1585.

Barker N, van Es JH, Kuipers J, Kujala P, van den Born M, Cozijnsen M, Haegebarth A, Korving J, Begthel H, Peters PJ, Clevers H (2007) Identification of stem cells in small intestine and colon by marker gene Lgr5. Nature 449(7165): 1003-1007.

Baron JA, Cole BF, Sandler RS, Haile RW, Ahnen D, Bresalier R, McKeown-Eyssen G, Summers RW, Rothstein R, Burke CA, Snover DC, Church TR, Allen JI, Beach M, Beck GJ, Bond JH, Byers T, Greenberg ER, Mandel JS, Marcon N, Mott LA, Pearson L, Saibil F, van Stolk RU (2003) A randomized trial of aspirin to prevent colorectal adenomas. $N$ Engl J Med 348(10): 891-899.

Bhala N, Emberson J, Merhi A, Abramson S, Arber N, Baron JA, Bombardier C, Cannon C, Farkouh ME, FitzGerald GA, Goss P, Halls H, Hawk E, Hawkey C, Hennekens C, Hochberg M, Holland LE, Kearney PM, Laine L, Lanas A, Lance P, Laupacis A, Oates J, Patrono C, Schnitzer TJ, Solomon S, Tugwell P, Wilson K, Wittes J, Baigent C, Adelowo O, Aisen P, Al-Quorain A, Altman R, Bakris G, Baumgartner H, Bresee C, Carducci M, Chang DM, Chou CT, Clegg D, Cudkowicz M, Doody L, El Miedany Y, Falandry C, Farley J, Ford L, GarciLosa M, Gonzalez-Ortiz M, Haghighi M, Hala M, Iwama T, Jajic Z, Kerr D, Kim HS, Kohne C, Koo BK, Martin B, Meinert C, Muller N, Myklebust G, Neustadt D, Omdal R, Ozgocmen S, Papas A, Patrignani P, Pelliccia F, Roy V, Schlegelmilch I, Umar A, Wahlstrom O, Wollheim F, Yocum S, Zhang XY, Hall E, McGettigan P, Midgley R, Moore RA, Philipson R, Curtis S, Reicin A, Bond J, Moore A, Essex M, Fabule J, Morrison B, Tive L, Davies K, Yau F, Coxib Traditional NT (2013) Vascular and upper gastrointestinal effects of non-steroidal anti-inflammatory drugs: metaanalyses of individual participant data from randomised trials. Lancet 382(9894): 769-779.

Bharti AC, Aggarwal BB (2002) Chemopreventive agents induce suppression of nuclear factor- $\mathrm{\kappa B}$ leading to chemosensitization. Ann NY Acad Sci 973(1): 392-395.

Bosset JF, Collette L, Calais G, Mineur L, Maingon P, Radosevic-Jelic L, Daban A, Bardet E, Beny A, Ollier JC (2006) Chemotherapy with preoperative radiotherapy in rectal cancer. $N$ Engl J Med 355(11): $1114-1123$.

Burn J, Gerdes AM, Macrae F, Mecklin JP, Moeslein G, Olschwang S, Eccles D, Evans DG, Maher ER, Bertario L, Bisgaard ML, Dunlop MG, Ho JW, Hodgson SV, Lindblom A, Lubinski J, Morrison PJ, Murday V, Ramesar R, Side L, Scott RJ, Thomas HJ, Vasen HF, Barker G, Crawford G, Elliott F, Movahedi M, Pylvanainen K, Wijnen JT, Fodde R, Lynch HT, Mathers JC, Bishop DT (2011) Long-term effect of aspirin on cancer risk in carriers of hereditary colorectal cancer: an analysis from the CAPP2 randomised controlled trial. Lancet 378(9809): 2081-2087. 
Cho RW, Clarke MF (2008) Recent advances in cancer stem cells. Curr Opin Genet Dev 18(1): 48-53.

Chua YJ (2010) Pathological complete response: still a relevant endpoint in rectal cancer? Lancet Oncol 11(9): 807-808.

Clendening JW, Pandyra A, Boutros PC, Ghamrasni SE, Khosravi F, Trentin GA, Martirosyan A, Hakem A, Hakem R, Jurisica I, Penn LZ (2010) Dysregulation of the mevalonate pathway promotes transformation. Proc Natl Acad Sci USA 107(34): 15051-15056.

Cox AD, Fesik SW, Kimmelman AC, Luo J, Der CJ (2014) Drugging the undruggable RAS: Mission Possible? Nat Rev Drug Discov 13(11): 828-851.

Coyle C, Cafferty FH, Vale C, Langley RE (2016) Metformin as an adjuvant treatment for cancer: a systematic review and meta-analysis. Ann Oncol 27(12): 2184-2195.

de Campos-Lobato LF, Stocchi L, da Luz Moreira A, Geisler D, Dietz DW, Lavery IC, Fazio VW, Kalady MF (2011) Pathologic complete response after neoadjuvant treatment for rectal cancer decreases distant recurrence and could eradicate local recurrence. Ann Surg Oncol 18(6): 1590-1598.

den Dulk M, Putter H, Collette L, Marijnen CA, Folkesson J, Bosset JF, Rodel C, Bujko K, Pahlman L, van de Velde CJ (2009) The abdominoperineal resection itself is associated with an adverse outcome: the European experience based on a pooled analysis of five European randomised clinical trials on rectal cancer. Eur J Cancer 45(7): 1175-1183.

Dhadda AS, Dickinson P, Zaitoun AM, Gandhi N, Bessell EM (2011) Prognostic importance of Mandard tumour regression grade following pre-operative chemo/radiotherapy for locally advanced rectal cancer. Eur $J$ Cancer 47(8): 1138-1145.

Dworak O, Keilholz L, Hoffmann A (1997) Pathological features of rectal cancer after preoperative radiochemotherapy. Int J Colorectal Dis 12(1): $19-23$.

Giardiello FM, Hamilton SR, Krush AJ, Piantadosi S, Hylind LM, Celano P, Booker SV, Robinson CR, Offerhaus GJA (1993) Treatment of colonic and rectal adenomas with sulindac in familial adenomatous polyposis. $\mathrm{N} \mathrm{Engl} J$ Med 328(18): 1313-1316.

Goldstein J, Brown M (1990) Regulation of the mevalonate pathway. Nature 343: 425-430.

Gray R, Barnwell J, McConkey C, Hills RK, Williams NS, Kerr DJ, Grp QC (2007) Adjuvant chemotherapy versus observation in patients with colorectal cancer: a randomised study. Lancet 370(9604): 2020-2029.

Greenhough A, Smartt HJM, Moore AE, Roberts HR, Williams AC, Paraskeva C, Kaidi A (2009) The COX-2/PGE(2) pathway: key roles in the hallmarks of cancer and adaptation to the tumour microenvironment. Carcinogenesis 30(3): 377-386.

Guertin D, Sabatini D (2007) Defining the role of mTOR in cancer. Cancer Cell 12: 9-22.

Habr-Gama A, Perez R, Proscurshim I, Gama-Rodrigues J (2010) Complete clinical response after neoadjuvant chemoradiation for distal rectal cancer. Surg Oncol Clin N Am 19(4): 829-845.

Habr-Gama A, Sabbaga J, Gama-Rodrigues J, Sao Juliao GP, Proscurshim I, Bailao Aguilar P, Nadalin W, Perez RO (2013) Watch and wait approach following extended neoadjuvant chemoradiation for distal rectal cancer: are we getting closer to anal cancer management? Dis Colon Rectum 56(10): 1109-1117.

Han YD, Kim WR, Park SW, Cho MS, Hur H, Min BS, Baik SH, Lee KY, Kim NK (2015) Predictors of pathologic complete response in rectal cancer patients undergoing total mesorectal excision after preoperative chemoradiation. Medicine (Baltimore) 94(45): e1971.

Hanahan D, Weinberg R (2011) Hallmarks of Cancer: the next generation. Cell 144(4): 646-674.

Heald RJ, Husband EM, Ryall RDH (1982) The mesorectum in rectal cancer surgery-the clue to pelvic recurrence? Br J Surg 69(10): 613-616.

Holm T, Ljung A, Häggmark T, Jurell G, Lagergren J (2007) Extended abdominoperineal resection with gluteus maximus flap reconstruction of the pelvic floor for rectal cancer. Br J Surg 94(2): 232-238.

Illum H, Wang DH, Dowell JE, Hittson WJ, Torrisi JR, Meyer J, Huerta S (2015) Phase I dose escalation trial of nitroglycerin in addition to 5 -fluorouracil and radiation therapy for neoadjuvant treatment of operable rectal cancer. Surgery 158(2): 460-465.

Jeong YK, Kim MS, Lee JY, Kim EH, Ha H (2015) Metformin radiosensitizes p53-deficient colorectal cancer cells through induction of G2/M arrest and inhibition of DNA repair proteins. PLoS One 10(11): e0143596.
Kapiteijn E, Marijnen CA, Nagtegaal ID, Putter H, Steup WH, Wiggers T, Rutten HJ, Pahlman L, Glimelius B, van Krieken JH, Leer JW, van de Velde CJ (2001) Preoperative radiotherapy combined with total mesorectal excision for resectable rectal cancer. $N$ Engl J Med 345(9): 638-646.

Karin M, Greten FR (2005) NF kappa B: linking inflammation and immunity to cancer development and progression. Nat Rev Immunol 5(10): 749-759.

Katz MS, Minsky BD, Saltz LB, Riedel E, Chessin DB, Guillem JG (2005) Association of statin use with a pathologic complete response to neoadjuvant chemoradiation for rectal cancer. Int J Radiat Oncol Biol Phys 62(5): 1363-1370.

Korinek V, Barker N, Moerer P, van Donselaar E, Huls G, Peters PJ, Clevers H (1998) Depletion of epithelial stem-cell compartments in the small intestine of mice lacking Tcf-4. Nat Genet 19(4): 379-383.

Kusama T, Mukai M, Tatsuta M, Matsumoto Y, Nakamura H, Inoue M (2003) Selective inhibition of cancer cell invasion by a geranylgeranyltransferase-1 inhibitor. Clin Exp Metastasis 20(6): 561-567.

Lee J, Kim T (2014) Type II Diabetes, Metformin use, and colorectal neoplasia:mechanism of action and implications for future research. Curr Colorectal Cancer Rep 10: 105-113.

Leong KJ, Beggs A, James J, Morton DG, Matthews GM, Bach SP (2014) Biomarker-based treatment selection in early-stage rectal cancer to promote organ preservation. Br J Surg 101(10): 1299-1309.

Leong KJ, Wei W, Tannahill LA, Caldwell GM, Jones CE, Morton DG, Matthews GM, Bach SP (2011) Methylation profiling of rectal cancer identifies novel markers of early-stage disease. Br J Surg 98(5): 724-734.

Lim SH, Kim TW, Hong YS, Han SW, Lee KH, Kang HJ, Hwang IG, Lee JY, Kim HS, Kim ST, Lee J, Park JO, Park SH, Park YS, Lim HY, Jung SH, Kang WK (2015) A randomised, double-blind, placebo-controlled multicentre phase III trial of XELIRI/FOLFIRI plus simvastatin for patients with metastatic colorectal cancer. Br J Cancer 113(10): 1421-1426.

Lim T, Lee I, Kim J, Kang WK (2015) Synergistic Effect of Simvastatin Plus Radiation in Gastric Cancer and Colorectal Cancer: Implications of BIRC5 and Connective Tissue Growth Factor. Int J Radiat Oncol Biol Phys 93(2): 316-325.

Lipkin SM, Chao EC, Moreno V, Rozek LS, Rennert H, Pinchev M, Dizon D, Rennert G, Kopelovich L, Gruber SB (2010) Genetic variation in 3-hydroxy-3-methylglutaryl CoA reductase modifies the chemopreventive activity of statins for colorectal cancer. Cancer Prev Res 3(5): 597-603.

Mace AG, Gantt GA, Skacel M, Pai R, Hammel JP, Kalady MF (2013) Statin therapy is associated with improved pathologic response to neoadjuvant chemoradiation in rectal cancer. Dis Colon Rectum 56(11): 1217-1227.

Mace AG, Pai RK, Stocchi L, Kalady MF (2015) American joint committee on cancer and college of american pathologists regression grade. Dis Colon Rectum 58(1): 32-44.

MacFarlane JK, Ryall RDH, Heald RJ (1993) Mesorectal excision for rectal cancer. Lancet 341(8843): 457-460.

Mandard A-M, Dalibard F, Mandard J-C, Marnay J, Henry-Amar M, Petiot J-F, Roussel A, Jacob J-H, Segol P, Samama G, Ollivier J-M, Bonvalot S, Gignoux M (1994) Pathologic assessment of tumor regression after preoperative chemoradiotherapy of esophageal carcinoma. Clinicopathologic correlations. Cancer 73(11): 2680-2686.

Mantovani A, Allavena P, Sica A, Balkwill F (2008) Cancer-related inflammation. Nature 454(7203): 436-444.

Martin ST, Heneghan HM, Winter DC (2012) Systematic review and meta-analysis of outcomes following pathological complete response to neoadjuvant chemoradiotherapy for rectal cancer. Br J Surg 99(7): 918-928.

Moher D, Liberati A, Tetzlaff J, Altman DG (2009) Preferred reporting items for systematic reviews and meta-analyses: the PRISMA statement. PLoS Med 6: e1000097.

Morin PJ, Sparks AB, Korinek V, Barker N, Clevers H, Vogelstein B, Kinzler KW (1997) Activation of beta-catenin-Tcf signaling in colon cancer by mutations in beta-catenin or APC. Science 275(5307): $1787-1790$.

National Cancer Intelligence Network (2009) Colorectal Cancer Survival by Stage. National Cancer Intelligence Network: Leeds, UK.

National Institute for Health and Care Excellence (NICE) (2014) Colorectal Cancer: The Diagnosis and Management of Colorectal Cancer CG131. NICE CG131. NICE: London, UK.

Nymann T, Jess P, Christiansen J (1995) Rate and treatment of pelvic recurrence after abdominoperineal resection and low anterior resection for rectal cancer. Dis Colon Rectum 38(8): 799-802. 
Office for National Statistics (2014) Cancer Survival in England: Adults Diagnosed 2008 to 2012, followed up to 2013. ONS: Newport, UK.

Oh BY, Park YA, Huh JW, Cho YB, Yun SH, Lee WY, Park HC, Choi DH, Park YS, Kim HC (2016) Metformin enhances the response to radiotherapy in diabetic patients with rectal cancer. J Cancer Res Clin Oncol 142(6): 1377-1385.

Oliver MF (1991) Might treatment of hypercholesterolaemia increase noncardiac mortality? Lancet 337(8756): 1529-1531.

Osmak M (2012) Statins and cancer: Current and future prospects. Cancer Lett 324(1): 1-12.

Pahlman L, Glimelius B, Cedermark B, Lundell G, Rubio C, Rutqvist LE, Wilking N, Ost A, Brismar B, Ewerth S, Forsgren L, Johansson C, Magnusson I, Sundelin P, Svensson C, Tornberg B, Theve T, Fenyo G, Svensson SO, Goldman S, Molin K, Bark S, Sundblad M, Dalen J, Lindholmer C, Robertsson B, Ohman U, Nilsson SE, Dahlberg M, Graf W, JanssonFrykholm G, Lindmark G, Westman M, Liljeholm H, Bendtsen O, Ljungquist U, Nihlberg A, Heuman R, Lorentz T, BisgaardPedersen A, Bergstrom S, Krog M, Tuvesson T, Edman P, Lindstrom C, Sandhammar B, Tyden G, Bergman L, Enander LK, Underskog I, Sellstrom H, Armatys P, Moell P, Hellberg R, Stenstam B, Dafnis G, Hojer H, Baldetorp L, Hatschek T, Sjodahl R, Arbman G, Nilsson E, StorgrenFordell V, Hugander A, Lagerberg F, Simert G, delaRue RA, Aldman A, Lannerstad O, Gullstrand P, Arwidi A, Bohe M, Ekelund G, Jiborn H, Landberg T, Graffman S, Jansson O, Jeppson B, Sorbris R, Ohlsson E, Lenninger S, Hallden K, Norryd C, Adamsen S, Hultborn R, Nilsson S, Magnusson O, Soderberg HE, Lindberg B, Tveit E, Jansson R, Svensson JH, Gustafsson A, Almskog B, Salander H, Holmlund D, Filipsson S, Laino R, Athlin L, Bengtsson NO, Groman G, Lundegard G, Dedorson S, Henriksson G, Nordahl A, Ryd G, Edlund G, Svensson JO, Rutegard J, Fagerberg M, Edin K (1997) Improved survival with preoperative radiotherapy in resectable rectal cancer. $N$ Engl J Med 336(14): 980-987.

Peeters KCMJ, Marijnen CAM, Nagtegaal ID, Kranenbarg EK, Putter H, Wiggers T, Rutten H, Pahlman L, Glimelius B, Leer JW, van de Velde CJH (2007) The TME Trial After a Median Follow-up of 6 Years. Ann Surg 246(5): 693-701.

Piazuelo E, Lanas A (2015) NSAIDS and gastrointestinal cancer. Prostaglandins Other Lipid Mediat 120: 91-96.

Pierotti MA, Berrino F, Gariboldi M, Melani C, Mogavero A, Negri T, Pasanisi P, Pilotti S (2013) Targeting metabolism for cancer treatment and prevention: Metformin, an old drug with multi-faceted effects. Oncogene 32(12): 1475-1487.

Pilipshen SJ, Heilweil M, Quan SHQ, Sternberg SS, Enker WE (1984) Patterns of pelvic recurrence following definitive resections of rectal cancer. Cancer 53(6): 1354-1362.

Puvvada SD, Funkhouser WK, Greene K, Deal A, Chu H, Baldwin AS, Tepper JE, O'Neil BH (2010) NF-kB and Bcl-3 Activation Are Prognostic in Metastatic Colorectal Cancer. Oncology 78(3-4): 181-188.

Restivo A, Cocco IMF, Casula G, Scintu F, Cabras F, Scartozzi M, Zorcolo L (2015) Aspirin as a neoadjuvant agent during preoperative chemoradiation for rectal cancer. Br J Cancer 113(8): 1133-1139.

Rizos CV, Elisaf MS (2013) Metformin and cancer. Eur J Pharmacol 705(1-3): 96-108.

Roh MS, Colangelo LH, O'Connell MJ, Yothers G, Deutsch M, Allegra CJ, Kahlenberg MS, Baez-Diaz L, Ursiny CS, Petrelli NJ, Wolmark N (2009) Preoperative multimodality therapy improves disease-free survival in patients with carcinoma of the rectum: NSABP R-03. J Clin Oncol 27(31): 5124-5130

Roth GJ, Stanford N, Majerus PW (1975) Acetylation of prostaglandin synthase by aspirin. Proc Natl Acad Sci USA 72(8): 3073-3076.

Rothwell PM, Wilson M, Elwin C-E, Norrving B, Algra A, Warlow CP, Meade TW (2010) Long-term effect of aspirin on colorectal cancer incidence and mortality: 20-year follow-up of five randomised trials. Lancet 376(9754): 1741-1750.

Rothwell PM, Wilson M, Price JF, Belch JFF, Meade TW, Mehta Z (2012) Effect of daily aspirin on risk of cancer metastasis: a study of incident cancers during randomised controlled trials. Lancet 379(9826): 1591-1601.

Rullier E, Goffre B, Bonnel C, Zerbib F, Caudry M, Saric J (2001) Preoperative Radiochemotherapy and Sphincter-Saving Resection for T3 Carcinomas of the Lower Third of the Rectum. Ann Surg 234(5): 633-640.

Ryan JE, Warrier SK, Lynch AC, Ramsay RG, Phillips WA, Heriot AG (2016) Predicting pathological complete response to neoadjuvant chemoradiotherapy in locally advanced rectal cancer: a systematic review. Colorectal Dis 18(3): 234-246.

Rödel C, Martus P, Papadoupolos T, Füzesi L, Klimpfinger M, Fietkau R, Liersch T, Hohenberger W, Raab R, Sauer R, Wittekind C (2005) Prognostic significance of tumor regression after preoperative chemoradiotherapy for rectal cancer. J Clin Oncol 23(34): 8688-8696.

Saamarthy K, Bjorner S, Johansson M, Landberg G, Massoumi R, Jirstrom K, Masoumi K (2015) Early diagnostic value of Bcl-3 localization in colorectal cancer. BMC Cancer 15: 341.

Saber MM, Galal MA, Ain-Shoka AA, Shouman SA (2016) Combination of metformin and 5-aminosalicylic acid cooperates to decrease proliferation and induce apoptosis in colorectal cancer cell lines. $B M C$ Cancer 16(1): 126.

Sauer R, Becker H, Hohenberger W, Rodel C, Wittekind C, Fietkau R, Martus P, Tschmelitsch J, Hager E, Hess C, Karstens J, Liersch T, Schmidberger H, Raab R (2004) Preoperative versus postoperative chemoradiotherapy for rectal cancer. N Engl J Med 351(17): $1731-1740$

Schafer W, Kim R, Sterne R, Thorner J, Kim S, Rine J (1989) Genetic and pharmacological suppression of oncogenic mutations in ras genes of yeast and humans. Science 245(4916): 379-385.

Sebag-Montefiore D, Stephens RJ, Steele R, Monson J, Grieve R, Khanna S, Quirke P, Couture J, de Metz C, Myint AS, Bessell E, Griffiths G, Thompson LC, Parmar M (2009) Preoperative radiotherapy versus selective postoperative chemoradiotherapy in patients with rectal cancer (MRC CR07 and NCIC-CTG C016): a multicentre, randomised trial. Lancet 373(9666): 811-820.

Shihab OC, Brown G, Daniels IR, Heald RJ, Quirke P, Moran BJ (2010) Patients with low rectal cancer treated by abdominoperineal excision have worse tumors and higher involved margin rates compared with patients treated by anterior resection. Dis Colon Rectum 53(1): 53-56.

Siddiqui AA, Nazario H, Mahgoub A, Patel M, Cipher D, Spechler SJ (2009) For patients with colorectal cancer, the long-term use of statins is associated with better clinical outcomes. Dig Dis Sci 54(6): 1307-1311.

Skinner HD, Crane CH, Garrett CR, Eng C, Chang GJ, Skibber JM, Rodriguez-Bigas MA, Kelly P, Sandulache VC, Delclos ME, Krishnan S, Das P (2013) Metformin use and improved response to therapy in rectal cancer. Cancer Med 2(1): 99-107.

STAR-TREC Trial Protocol (2016) STAR-TREC: Saving the rectum by active surveillance or TransAnal surgery after (chemo)Radiotherapy versus Total mesorectal excision for early rectal cancer. ISRCTN Registry. BMC. Available at: www.isrctn.com/ISRCTN14240288.

Stoffregen CC, Odin EA, Carlsson GU, Kurlberg GK, Björkqvist HG, Tångefjord MT, Gustavsson BG (2016) Reduced folate and serum vitamin metabolites in patients with rectal carcinoma. Anticancer Drugs 27(5): 439-446.

TREC Trial Protocol (2010) TREC A randomised Phase II feasibility study to compare radical TME surgery versus short course preoperative radiotherapy with delayed local excision for treatment of early Rectal cancer. University of Birmingham: Birmingham, UK.

Van der Flier LG, Sabates-Bellver J, Oving I, Haegebarth A, De Palo M, Anti M, Van Gijn ME, Suijkerbuijk S, Van de Wetering M, Marra G, Clevers H (2007) The intestinal Wnt/TCF signature. Gastroenterology 132(2): 628-632.

Vinogradova Y, Coupland C, Hippisley-Cox J (2011) Exposure to statins and risk of common cancers: a series of nested case-control studies. BMC Cancer 11: 409.

Vinogradova Y, Hippisley-Cox J, Coupland C, Logan RF (2007) Risk of colorectal cancer in patients prescribed statins, nonsteroidal antiinflammatory drugs, and cyclooxygenase-2 inhibitors: nested case-control study. Gastroenterology 133(2): 393-402.

Wachtershauser A (2001) HMG-CoA reductase inhibitor mevastatin enhances the growth inhibitory effect of butyrate in the colorectal carcinoma cell line Caco-2. Carcinogenesis 22(7): 1061-1067.

Waddell WR, Loughry RW (1983) Sulindac for polyposis of the colon. J Surg Oncol 24(1): 83-87.

Wang D (2006) Prostaglandins and cancer. Gut 55(1): 115-122.

Wang D, DuBois RN (2009) The role of COX-2 in intestinal inflammation and colorectal cancer. Oncogene 29(6): 781-788.

Wang LW, Hsiao CF, Chen WT, Lee HH, Lin TC, Chen HC, Chen HH, Chien CR, Lin TY, Liu TW (2014) Celecoxib plus chemoradiotherapy for 
locally advanced rectal cancer: a phase II TCOG study. J Surg Oncol 109(6): 580-585.

Wheeler JMD, Warren BF, Mortensen NJM, Ekanyaka N, Kulacoglu H, Jones AC, George BD, Kettlewell MGW (2002) Quantification of Histologic Regression of Rectal Cancer After Irradiation. Dis Colon Rectum 45(8): 1051-1056.

Yaffee P, Osipov A, Tan C, Tuli R, Hendifar A (2015) Review of systemic therapies for locally advanced and metastatic rectal cancer. J Gastrointest Oncol 6(2): 185-200.

Zannella VE, Dal Pra A, Muaddi H, McKee TD, Stapleton S, Sykes J, Glicksman R, Chaib S, Zamiara P, Milosevic M, Wouters BG, Bristow RG, Koritzinsky M (2013) Reprogramming metabolism with metformin improves tumor oxygenation and radiotherapy response. Clin Cancer Res 19(24): 6741-6750.

This work is licensed under the Creative Commons Attribution 4.0 International License. To view a copy of this license, visit http://creativecommons.org/licenses/by/4.0/

(C) The Author(s) named above 2017 